\title{
Analyses on the Present Situation and Prospect of Confucius Institutes in the Philippines
}

\author{
Lili XU \\ The Southern Base of Confucius Institute Headquarters, \\ Xiamen University \\ Xiamen, China
}

\author{
He WANG* \\ The Southern Base of Confucius Institute Headquarters, \\ Xiamen University \\ Xiamen, China
}

\begin{abstract}
The construction and development of the Confucius Institute (CI) is of great significance to China, as it provides a platform for educational and cultural exchanges and cooperation between China and the rest of the world. So far, four CIs have been established in the Philippines. Based on the analysis of the current operation model, business scope, student sources, service types and publicity channels of the four CIs, this paper discusses the challenges faced by the current CIs in the context of the Philippine society. Moreover, it puts forward specific suggestions on how to cope with the challenges and achieve in-depth development through upgrading business scope, application of digital technology and publicity channels.
\end{abstract}

Keywords-The Philippines; Confucius Institutes; mandarin teaching; Publicity channels

\section{INTRODUCTION}

On November 21, 2004, the world's first CI was established in Seoul, Korea. Since then, the CIs have experienced a rapid development. As of December 31, 2018, there have been 548 CIs and 1139 Confucius Classrooms in the world [1]. The CIs Headquarters was set in Beijing. As non-profit educational institutions, the CIs aim at teaching Chinese and introducing Chinese culture. In the form of Sino-foreign cooperation, the CIs provide Chinese language and culture learners with the resources and opportunities to learn Mandarin and understand contemporary China. Among these CIs, four are located in the Philippines.

\section{THE DEVELOPMENT OF THE CONFUCIUS INSTITUTES IN THE PHILIPPINES}

\section{A. Management and operation of CIs in the Philippines}

From October 2006 to October 2015, four CIs were established in the Philippines, including CI at Ateneo de Manila University (2006), CI at Bulacan State University(2009), CI at Angeles University Foundation(2010) and CI at University of the Philippines(2015).The four CIs are all operated under a three-party cooperation model, which involves the host universities in the Philippines, the Chinese partner universities and the CI Headquarters [2]. The operation of the CIs shall be jointly funded by the CI Headquarters and the host universities in a 1:1 ratio. The CI Headquarters will support the CIs with a start-up fund and annual project funding, provide teaching resources such as textbooks and multimedia

This research was financially supported by Humanities and Social Science Foundation of Ministry of Education of China "The Strategies of the popularization of Mandarin Chinese in the Philippines under 'One Belt One Road'” (Grant No.: 18YJC740118). courseware, authorize the use of online courses, and send Chinese professional teachers and volunteer teachers according to the needs of the Philippine universities. Meanwhile, the host universities provide venues and office facilities for the CIs. They also provide administrative staff for CIs and pay for relevant expenses. Under this cooperation model, the host universities serve as a platform, enable the CIs to introduce their courses and activities to a great number of local students in a very short time, and effectively alleviate the possible "unacculturation" of CIs as cross-cultural language institutions in the Philippines. At the same time, as the host universities, they expanded their field of service to the local community and enhanced their own comprehensive strength. Moreover, the cooperation between Chinese and Philippine universities also provides opportunities to promote inter-school exchanges and cultivate their students' international vision. To manage the CIs through cooperation and negotiation, the three parties aims to achieve mutual benefits and win-win situations.

\section{B. Services provided by the CIs in the Philippines}

The services of the four CIs are mainly focus on language teaching and cultural exchanges. They also offer customized Chinese and cultural courses, organize local teacher training, teaching seminars, lectures, workshops, community cultural activities, etc. And the four CIs also encourage and organize students to take the HSK (Chinese Proficiency Test) and HSKK (Chinese Speaking Proficiency Test), YCT (Youth Chinese Test) and BCT (Business Chinese Test). As of April 2019, CI at Ateneo de Manila University has become one of the overseas test sites for HSK/HSKK/YCT/BCT and International Chinese Teacher Certificate Examination. CI at Angeles University Foundation has become one of the overseas test sites for HSK/HSKK/YCT and International Chinese Teacher Certificate Examination. CI at Bulacan State University has become one of the overseas test sites for HSK/HSKK. In addition, the CIs also provide some other services such as translation, scholarship application and education consulting, etc.

\section{Clients of the CIs in the Philippines}

At present, the four CIs provide teaching and service to various groups of learners, including students in primary/middle schools, employees in government agencies, enterprises, social groups and other individual learners who want to learn Chinese. The CIs' work is mainly based on their teaching on campus; however, each CI has its own focus on the 
target groups. For example, CI at Ateneo de Manila University has opened a new office in Makati, the commercial center of metro-manila, off its main campus. The new office provides charged Mandarin courses to professionals from business departments and diplomatic embassy. CI at Bulacan State University focuses on teaching mandarin in universities. Its priority is to bring Mandarin into the university's credit system. $\mathrm{CI}$ at Angeles University Foundation is the partner of the SPFL project of the Philippine Ministry of Education. It is responsible for the curriculum design of mandarin course in Philippine public secondary schools and made effort to integrate mandarin course into the Philippine basic education system. In addition, its core task is to train Philippine Chinese teachers and compile localized Chinese textbooks. CI at University of the Philippines, though just opened in October 2015, relies on the special status and resources of its host university, has developed rapidly since its establishment. Now the CI has three main sources of students, including learners from nine campuses of the host university, Philippine government agencies and 145 city colleges affiliated to the League of the Philippines Cities.

\section{Publicity channels and service type}

As the CIs are set in local universities, the work of CIs should be conducted under the guidance and within the framework of the host universities. In terms of publicity, the job is mainly done by the university and CI itself, via Chinese embassies and consulates, local Chinese communities, local Chinese-funded companies and local medias including paper, broadcast and TV. The self-built media of the four CIs (including official websites and Wechat public accounts) also played a certain role in the promotion [3]. At present, the teaching and activities of the four CIs are mainly conducted off-line. Many students take classes in CI classrooms. While in some cases, the CIs would dispatch their teachers to teach in short-term or long-term. By the end of 2017, the number of students in the CI at Ateneo de Manila University had increased to 16,433. The total number of registered students in CI at Bulacan State University had reached 3,700. While the number of teaching sites in CI at Angeles University Foundation had reached 95, with 1108 classes and 30,118 students [4]. As of April 2019, CI at University of the Philippines has recruited more than 1,000 students.

\section{ChALlENGES IN THE DEVELOPMENT OF THE CIS IN THE PHILIPPINES}

As an emerging language and culture education institution, CI has developed rapidly. In the Philippines, Chinese language education has experienced nearly 120 years exploration, providing sufficient soil for the popularity of Chinese in local communities. Today, the "one belt and one road" initiative has accelerated and deepened the cooperation between China and Philippines in various fields, which draws more attentions to Chinese learning from people of all works of lives in the Philippines. On this basis, the CIs have made great efforts to develop Chinese teaching in the mainstream local communities. It has achieved remarkable results via enhancing cooperation with Philippine government agencies, increasing interaction with local communities, and actively promoting the Chinese curriculum to enter the local national education system. However, the CIs face many challenges.

\section{A. Limitations in CI's operation model and the lack of overall regional agenda for the four CIs}

The four CIs are all established in influential universities in the countries. Among them, the University of the Philippines is the top one university in the country. Ateneo de Manila University is one of the four famous universities in the Philippines. Both universities are cradles for Philippine politicians and business elites. Bulacan State University and Angeles University Foundation are also very influential in their cities. Establishing in these famous universities can be a favorable factor for the CIs' success in the country. However, this operation model can also affect and restrict the development of CIs. Frist, since the CIs should comply with the unified development plan of the host universities. Therefore, the CIs are lack of the initiative in certain key matters like student enrollment, especially for those CIs in public universities. Second, the CIs are lack of financial independence. The annual funds from the Headquarters are directly allocated to the financial accounts of the host universities. Due to the long reimbursement process and complicated financial procedures, the launching of the CI activities is also affected to a certain extent.

In addition, there are also some problems in the communication and cooperation among the four CIs themselves. Although they are all under the unified management and guidance of the CI Headquarters, their business layout and development in the Philippines are basically carried out separately. Some CIs become business competitors due to their close geographical locations, which is not conducive to the integration of the overall resources and their coordinated development.

\section{B. The need of nationalization and specialization in the CI's work}

As newly established foreign language institutions in the Philippines, the CIs should quickly adapt to local learning needs. Therefore, their work focuses on language teaching and cultural activities. However, the language teaching and language services provided by the CIs still have difficulties in responding to the national and specialized needs of the country. In the perspective of language teaching, the CIs are lack of localized and specialized Chinese textbooks. The selection of CI teachers is mostly based on their teaching skill, so most of them have limited experience and ability in writing textbooks. In the perspective of cultural exchange, the cultural activities conducted by the four CIs cover a wide range of themes, including film, music, literature, food, drama, dance, Chinese medicine, architecture, books, fashion design, photography, science education, social issues, environmental protection, etc. However, the form of these activities is relatively simple. Most of them are unilateral, such as performances, exhibitions, lectures, traditional and folk culture experiences, etc. The cultural content presented by these activities is not profound enough, emphasizing too much on traditional culture instead of contemporary and pioneer culture. As to academic research, the work that have done by the CIs is far from satisfying the demand for information and services arising from the 
developing Sino-Philippine cooperation in the new era. The function of the CIs as a platform for cultural communication, information exchange and personnel exchange remain to be developed.

\section{The problems existed in institutional structure}

The composition of the CI staff is relatively simple. The Chinese staffs, who undertake most of the administration and teaching in the CIs, consists of a Chinese director, Chinese teachers and volunteer teachers. However, the staff members dispatched from China serves in terms, so they have to leave the positions when their tenure is over. Moreover, with limited number of teachers, all staff members can only devote their time to teaching tasks. Human resource shortages in both number of staff and type of professions prevent the CIs from providing other services other than teaching. In this context, it is very difficult for the CIs to expand its business field. Therefore, except for the trainees of the professional Chinese teachers' program, most of the Chinese learners trained by the CIs can hardly obtain attention in the human resource market. Most of them fail to show their value after a period of study in the CIs.

\section{Lack of diversity in teaching method and language} environment for continuous learning outside the CIs.

Under the influence of its colonial history, the Philippine society is almost "immerged" in English. English is used in official documents, newspapers, parliamentary debates and even TV and radio stations. Under this circumstance, Filipinos, even for those with Chinese origin, attach great importance to English. Hence, Chinese language education is lack of social environment. Moreover, traditional Chinese Medias have less impact on new media. This makes it difficult for many Chinese learners to access mandarin outside the classroom [5]. At present, there is no interactive Chinese learning platform in the Philippines. The official websites of the four CIs has just launched not long ago, which only present introductory information. No standard online course is provided, and the online learning resources and language tools are extremely limited. Due to the insufficient application of websites, the source of CI students is restricted in time and space. For the registered students, they will not be able to continue their learning and make improvement after a period of study in the CIs, unless more courses are offered, which is not conducive to the consolidation of learning outcomes and the sustained learning.

\section{SugGESTIONS ON THE DEVELOPMENT OF CIS IN THE PHILIPPINES IN THE NEW ERA}

A. Exploration in profit-orientated model:to expand the source of funds, strive for initiative in development, value regional cooperation and integrate resources

As nonprofit education organizations, on the basis of maximizing the public benefit, the CIs should also stress on their internal dynamic mechanism of sustainable development. At present, the Makati division of the CI at Ateneo de Manila University has already launched charged courses to public after investigating its targeted groups and their economic status. The income is used to improve teaching facilities, support independent CI activities and sponsor CI students. This model formed a positive circle of "production and sale". This partial commercial operation pattern, to some extent, increased CI's autonomy in throwing activities, also provided useful ideas for the sustainable development of the CIs. This example is worthwhile for other CIs to learn in practice. Other than learning from each other, the four CIs should also establish regional cooperation mechanisms, make full use of the resources of the host universities and their partner universities, integrate advantage in terms of curriculum construction, academic exchange, students' recruitment, and community service and so on, and avoid wasting resources and energy among the four CIs.

\section{B. Diversify the role of CI, transfer the CIs from language teaching classrooms into language service platforms}

With the proposing of One Belt And One Road initiative, China and the Philippines are having more cooperation in infrastructure construction, trade, culture, education and other fields. Hence, Chinese is increasing its practical and implicational value in the Philippine society, and more Filipinos are inspired to know Chinese culture. To take this opportunity, make use of the advantage of its location in local universities and base upon language teaching, the CIs should strengthen their construction in business content, innovate different ways of communication, to transfer from language learning classrooms to resource platforms that trigger cultural exchanges, scientific and technological cooperation and information consultation. The CIs are not only built as a bridge for Chinese to "go out", but also a platform for Philippine culture to "come in", and an information hub for cultural interaction between the two countries, which will better promote the cooperation and culture exchanges between the two countries [6]. Therefore, to guarantee their development and improvement, the CIs should establish specialized language service teams and attract more professionals to support the CIs' innovation in management, language service, academic research and information technology.

\section{The use of modern education technology and network to develop digital teaching and publicity channels}

In the new media environment, it is necessary to apply digital media as a tool to introduce Chinese language and culture to the world. For the moment, digital media can be used to support the development of the CIs in two ways: firstly, to transform the publicity channel into digital media; secondly, to upgrade their teaching and service in digital forms by using modern education technology. The Philippines is a significant user of online social media. According to Internet trend reports issued by Hootsuite, a famous global social media management platform, and the British consulting firm We Are social co., LTD., the Philippine people spend an average of 4 hours 17 minutes on Facebook, Twitter and other social media, ranking first in the world [7]. Online language learning and teaching system is no stranger to Filipinos. Therefore, the CIs should use new media especially the local mainstream media, applications and websites as publicity channels, to encourage interactions and communications on media such as Facebook, Twitter, etc., to establish an online community for the CIs. Meanwhile, the CIs should improve their website construction 
and the online learning resources development. For instance, the students should be able to complete course registration and enrollment, obtain library service, download learning recourse and communicate with students and teachers on the CI official websites.

\section{Establishing reputation and improving learning experience through alumni system}

Students are valuable sources to the CIs. The local students with passion for Chinese language and culture, having special feelings for the CI they studied in, can be very important social recourses for helping the CIs to improve their reputation. Therefore, the CIs should encourage communications among CI fellows and establish alumni association on the basis of their training types and student numbers. In this way, the CIs can serve as human resource advisors for the local Chinese enterprises, seeking and preserving bilingual professionals who are proficient in local politics, economics, history, culture and social customs. Besides, The CIs can also build organizations like PHILFEJA (Former Philippine union of Japanese students) and "The Krew" (The local student ambassador of Korean Culture Institute) to help their promotion and publicity in local communities. In addition, cooperation with local Chinese schools and enterprises can be an effective way to get more involved in the local society. The CIs can recommend schools for the new immigrants and offer customized training for the enterprises. Furthermore, the CIs should strengthen their cooperation with schools in both the Philippines and China, to serve as an information center and education agents, providing information and suggestions for Filipino students to study in China and for new immigrants to enroll in the Philippines. At last, the CIs can make use of their book resources to build cultural centers or CI libraries, encourage in-depth sinology research and support the project of "introduction of Chinese Classics to the world”.

\section{CONCLUSION}

To sum up, the four CIs in the Philippines have achieved remarkable results in terms of institutional construction, student source development, business expanding and reputation establishment in the past 13 years, but they also face a series of challenges. Nowadays, the cooperation and exchanges between China and the Philippines strengthens, so the implicational value of Chinese in the Philippines has increased greatly, providing an opportunity for the upgrading of the CIs. In response to the new environment and the new situation, the CIs should make good use of the existing foundation, explore new models for development, business scope, digital technology applications and publicity channels, and establish a multifunctional support system to better serve the national cultural education.

\section{REFERENCES}

[1] Confucius Institute Headquarters. http://www.hanban.org/confuciousinstitutes/node_10961.htm.2019-6-30

[2] Cao Diefeng, A Comparative Analysis of the Operational Modes and Decision-making Mechanisms of Language Promotion Agencies in Different Countries [J]. JOURNAL OF SOCIAL SCIENCE OF HUNAN NORMAL UNIVERSITY, 2014(01):142.(In Chinese)

[3] An Ran, Wei Xianpeng, Research on the Intercultural Communication Model of Confucius Institute [J]. INTERNATIONAL COMMUNICATIONS, 2014(1):53-55.(In Chinese).

[4] Lai Lindong, Research on the Integration of Confucius Institutes into Universities Under the Background of One Belt and One Road - Taking Four Confucius Institutes in the Philippines as An Example [J]. INTERNATIONAL AND COMPARATIVE EDUCATION, 2018(9):4 (In Chinese)

[5] Xu Lili, Yu Kehua, The strategies of the Popularization of Mandarin Chinese in the Philippines Under the New Situation of One Belt and One Road [J]. INTERNATIONAL CHINESE LANGUAGE EDUCATION, 2018(01):95. (In Chinese)

[6] Xu Lili, Yu Kehua, The strategies of the Popularization of Mandarin Chinese in the Philippines Under the New Situation of One Belt and One Road [J]. INTERNATIONAL CHINESE LANGUAGE EDUCATION, 2018(01):98.(In Chinese)

[7] Guangming Daily. http://news.gmw.cn/2017-02/04/content_23626479.htm, 2019-06-30. 